\title{
Correlação da variação da temperatura na parte sul do Oceano Atlântico com a precipitação pluviométrica no estado de Goiás
}

\author{
Correlation of the temperature changes on the south pacific ocean to the number of \\ rainfall days of the State of Goiás
}

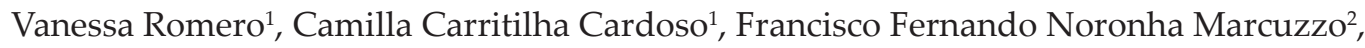 \\ Rosana Gonçalves Barros ${ }^{1}$ \\ ${ }^{1}$ IFTG - Instituto Federal de Tecnologia de Goiás \\ ${ }^{2}$ Companhia de Pesquisa de Recursos Minerais - Ministério de Minas e Energia
}

\begin{abstract}
Resumo
O estudo da influência das alternâncias da temperatura na porção sul do oceano Atlântico na variabilidade pluviométrica de uma região é importante em virtude dos impactos ocasionados pelas mudanças no padrão atmosférico. O objetivo deste estudo foi avaliar a influência da variação da temperatura da superfície do oceano Atlântico Sul, durante o período de 1982 a 2006, no número de dias de chuva do estado de Goiás. Para este estudo utilizou-se 114 estações pluviométricas cujos dados diários de precipitação pluvial diária foram obtidos da Rede Hidrometeorológica da Agência Nacional de Águas (ANA) e da Companhia de Pesquisa de Recursos Minerais /Serviço Geológico do Brasil (CPRM/SGB), sendo 88 estações com 30 anos de dados e 26 estações com 20 a 29 anos de dados. A metodologia utilizada para sistematizar os dados foi de regressão linear e polinomial (1982 a 2006), que estima um valor condicional esperado, e também a estatística descritiva, que permite calcular as medidas de tendência central e as medidas de dispersão. A análise estatística realizada neste estudo indicou que, durante os anos de 1982 a 2006, o mês de janeiro de 1985 (0,2 C acima da média histórica nas águas do Atlântico Sul) registrou o máximo número de dias de chuva em Goiás (24 dias), enquanto que os meses de julho (0,4 C) e agosto de 1988 (0,3 C), junho de 2002 (0,0 C) e julho de 2003 (0,3 C) não registraram ocorrência de chuva no estado. Logo, os valores máximos e mínimos de precipitação observados neste estudo não estavam sob influência de TSM segundo os resultados obtidos neste estudo. Palavras-chave: El Niño Oscilação-Sul, Número de Dias de Chuva, Anomalias de Temperatura da Superfície do Mar.
\end{abstract}

\begin{abstract}
The study of the influence of alternating temperature in the southern Atlantic Ocean in the rainfall variability from a region is important in impacts caused by changes in atmospheric pattern. The aim of this study was to evaluate the influence of the surface temperature of the South Atlantic Ocean, during the period 1982 to 2006, in the number of rainy days of the state of Goiás. For this study we used 114 daily rainfall stations whose data the maximum daily precipitation were obtained by the Hydrometeorological Network of the Water Agency of Brazil (WAB-ANA) and the Geological Survey of Brazil (GSB - CPRM / SGB), they being 88 stations with 30 years of data and 26 stations with 20 to 29 years of data. The methodology used to organize the data was linear and polynomial regression, estimating a conditional expected value, as well as descriptive statistics to calculate measures of central tendency and dispersion measures. Statistical analysis performed in this study indicated that during the years 1982 to 2006 , the month of January 1985 (0.2 Cabove the historical average in the waters of the South Atlantic) recorded the maximum number of days of rain in Goiás (24 days). While the months of July (0.4 C) and August 1988 (0.3 C), June 2002 (0.0 C) and July 2003 (0.3 C) did not record the occurrence of rain in the state. Therefore, the maximum and minimum values of precipitation observed in this study were not under the influence of SST. Keywords: El Niño Southern-Oscillation, Number of Days with Rain, Anomalies of Sea Surface Temperature.
\end{abstract}




\section{Introdução}

A progressiva crise ambiental instalada no Brasil desde o fim do século XX, em virtude do paradigma de desenvolvimento adotado (crescimento econômico em curto prazo à custa da degradação dos recursos naturais), somado às anomalias de Temperatura da Superfície do Mar (TSM) nos oceanos tropicais Pacífico e Atlântico, exerce influência sobre as condições climáticas globais ocasionando eventos extremos promotores de ondas de calor, aumento de vazões de rios, secas e cheias. No Pacífico Tropical, a presença de eventos quentes é denominada de El Niño, enquanto que a La Niña caracteriza-se por anomalias negativas de TSM (MARCUZZO et al., 2012).

Variações pluviométricas bruscas, e consequentes impactos sociais e econômicos na sociedade local, fomentam a importância de estudos sobre o comportamento atmosférico decorrente de extremos climáticos.

A região centro-oeste do Brasil não apresenta efeitos evidentes de mudanças no padrão das chuvas em razão dos fenômenos ENOS, mas há uma tendência de aumento destas no sul de Mato Grosso do Sul durante as manifestações do El Niño e previsão de chuva muito próxima da normal climatológica registrada para os estados de Mato Grosso, Mato Grosso do Sul e Goiás nos eventos de La Niña (SOARES et al., 2008).

Em um estudo com o Número de Dias de Chuva (NDC) no estado do Mato Grosso, Marcuzzo et al. (2012), verificaram que os meses os quais apresentaram tendência de decréscimo no NDC, em ordem decrescente, foram: junho, julho, maio, agosto, setembro, novembro, abril, dezembro, janeiro, fevereiro e outubro. Os mesmos autores relatam um decréscimo médio anual no NDC do Mato Grosso de -7,2\%.

Em um estudo da precipitação na região metropolitana de Goiânia e seu entorno, Cardoso et al. (2010) observaram que as chuvas anuais concentraram-se na região do município de Piracanjuba. Nas demais regiões dentro da área de estudos, as chuvas espacializaram-se de maneira homogênea variando na sua maioria entre $1400 \mathrm{~mm}$ e $1600 \mathrm{~mm}$. Na análise mensal das chuvas, pode-se notar um padrão na espacialização onde os maiores valores se concentram em uma faixa central que cobre toda a área de estudos de leste a oeste.

Romero e Marcuzzo (2013), em um estudo da influencia do El Niño e La Niña no NDC de Goiás, concluíram que a tendência central (média) para o NDC em Goiás mostrou uma maior proximidade com os valores máximos nos meses chuvosos (outubro a abril) em relação aos meses secos (maio a setembro), que tiveram maior proximidade com os valores mínimos. Além disso, os autores relatam que o maior desvio padrão foi obtido em janeiro $(3,6)$, considerado mês chuvoso, e o menor desvio padrão foi obtido em julho $(0,8)$, considerado mês seco.

Embora não tenha comprovação cientifica que o ENOS afete a região deste estudo, para o nordeste do país, anos de El Niño (La Niña), em geral, estão associados com escassez (chuvas mais abundantes), enquanto condições contrárias são observadas no sul e sudeste do país. Em geral, estas condições também estão relacionadas às ocorrências de dipolos de TSM no Atlântico Tropical. Anomalias positivas (negativas) de TSM nos setores norte (sul) dessa bacia, na maioria das vezes, também podem ocorrer em anos de El Niño, sendo as características contrárias observadas em anos de La Niña (ALVES et al., 2006).

Santos \& Manzi (2011) concluíram em pesquisa sobre a relação da temperatura dos oceanos tropicais (Pacífico, Atlântico e Índico) com eventos extremos de precipitação no estado do Ceará, que a anomalia positiva de TSM (Temperatura na Superfície do Mar) ao norte do equador. No Oceano Atlântico, induz que a ZCIT (Zona de Convergência Intertropical) se desloque para o norte cearense, inibindo os eventos chuvosos, e aumentando o número de dias consecutivos secos sobre o norte do estado.

Em anos de ocorrência de El Niño, cerca de 52\% dos valores de precipitação de Mossoró (Rio Grande do Norte) estiveram abaixo da média histórica. Com relação aos anos nos quais ocorreu o fenômeno La Niña, verificou-se pluviosidade acima da média em 46\% dos mesmos (PEREIRA et al., 2010).

Devido à escassez de estudos publicados sobre o tema, o objetivo deste estudo foi avaliar a influência da variação da temperatura do oceano Atlântico Sul no número de dias de precipitação pluviométrica do estado de Goiás, entre os anos de 1982 a 2006.

\section{Material e Métodos}

\subsection{Caracterização da área de estudo e dados utilizados}

O estado de Goiás localiza-se na região centro-oeste do Brasil (Figura 1), no Planalto Central, e possui uma área de 340.103,467 km2 (IBGE, 2010). Está delimitado pelos estados do Tocantins, Bahia, Minas Gerais, Mato Grosso do Sul, Mato Grosso e pelo Distrito Federal.

O uso do solo em Goiás está concentrado em atividades pecuaristas (Figura 1), que podem ser afetadas pela precipitação pluviométrica. Para este estudo, utilizou-se 114 estações pluviométricas, para o 


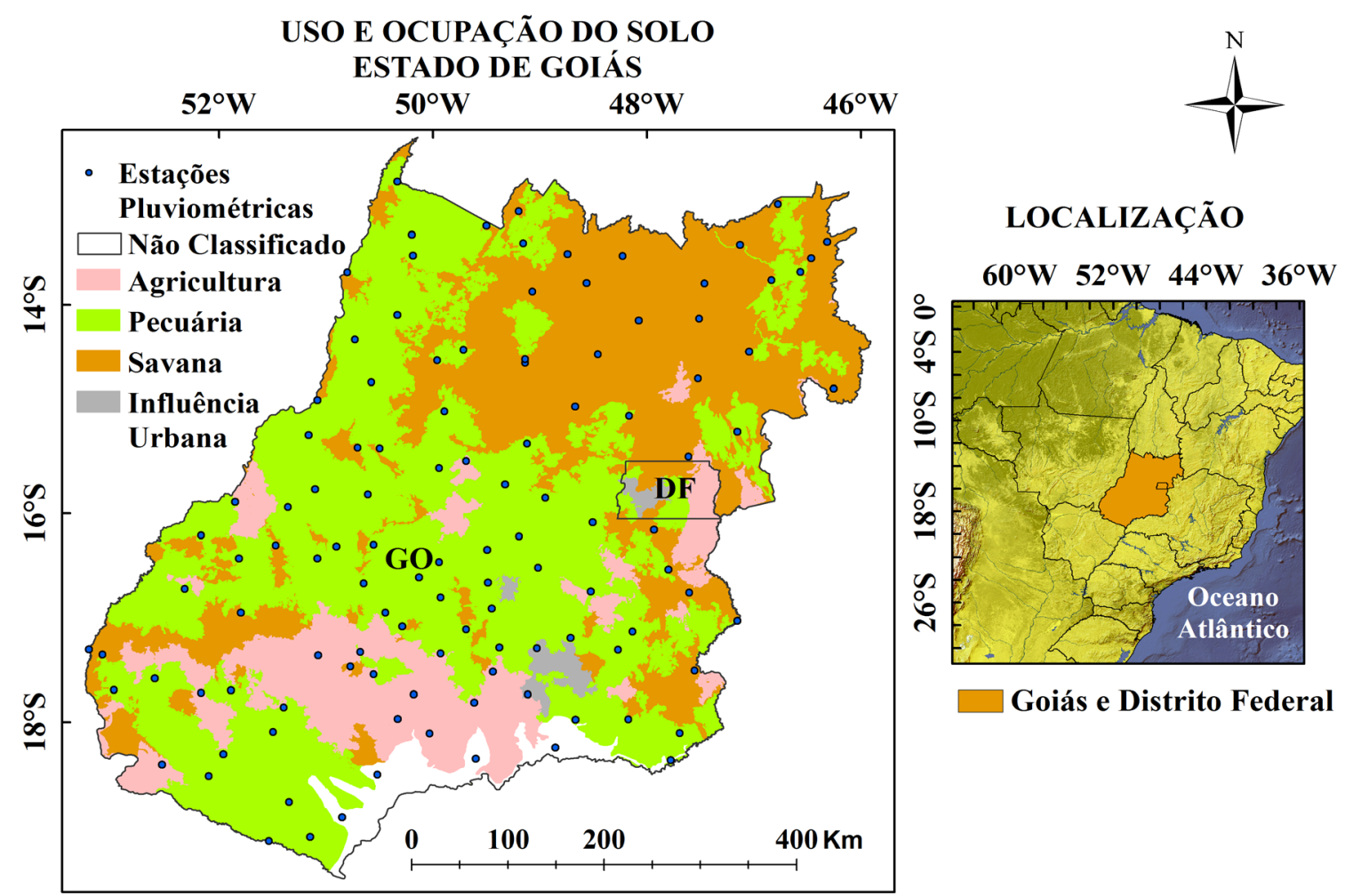

Figura 1.Uso e ocupação do solo e localização do estado de Goiás.

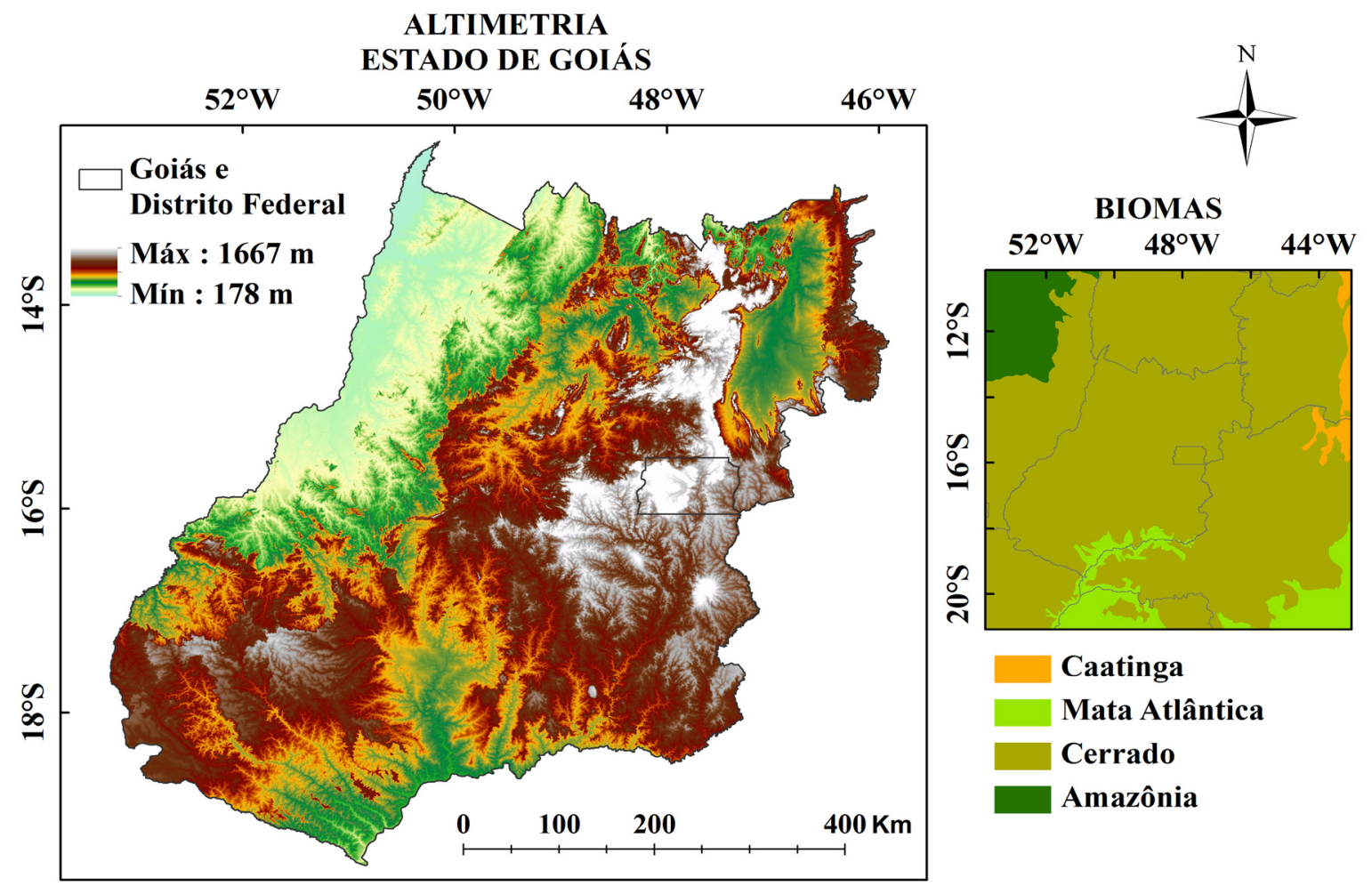

Figura 2.Altimetria e biomas do estado de Goiás. 
estado de Goiás (Figura 1), cujos dados de precipitação diária foram obtidos da Rede Hidrometeorológica da Agência Nacional de Águas (ANA) e da Companhia de Pesquisa de Recursos Minerais/Serviço Geológico do Brasil (CPRM/SGB), publicados por Pinto et al. (2011). Foram 88 estações com 30 anos de dados e 26 estações com 20 a 29 anos de dados.

Neste trabalho, também utilizaram-se dados hipsométricos do projeto SRTM (Shuttle Radar Topology Mission) com resolução de 90 metros. As imagens SRTM foram agrupadas em um programa GIS (Geographic Information System) e posteriormente o MDE (Modelo Digital de Elevação). Foi delimitado, permitindo analisar a hipsometria do estado de Goiás, que se caracteriza por terras cujas altitudes variam de 178 a 1667 metros, resultando num gradiente altimétrico de 1.489 metros (Figura 2), visando o auxilio da discussão dos resultados. As terras mais altas de Goiás localizam-se na região do Distrito Federal e proximidades. Em sua maior parte, Goiás encontra-se inserido no bioma do cerrado, pequena parte do estado está inserida na mata atlântica (Figura 2).

Com uma população de 6.003.788 habitantes e 246 municípios, o estado de Goiás possui baixa densidade demográfica sendo a cidade mais densa do estado, a capital, Goiânia, com aproximadamente
103 hab.(km²)-1. O município de menor densidade demográfica é Aporé (Figura 3) com aproximadamente 1 hab.(km²)-1 (IBGE, 2010). Segundo a classificação climática de Köppen, existem três climas atuantes no estado: o clima tropical com estação seca no inverno (Aw), o clima temperado úmido com inverno seco e verão quente (Cwa) e o clima temperado úmido com inverno seco e verão temperado (Cwb) (Figura 3). A espacialização pluviométrica em Goiás e sua correlação com o clima é discutida por Costa et al. (2012).

A metodologia utilizada para sistematizar os dados foi de regressão polinomial, que estima um valor condicional esperado, e também a estatística descritiva, que permite calcular as medidas de tendência central e as medidas de dispersão. Os dados de precipitação foram completos nesse período, sendo realizado pouco preenchimento de falhas.

Utilizando-se as medidas de tendência central e de dispersão, podem-se verificar analiticamente os parâmetros e observar se as amostras são diferentes ou semelhantes para os dados intra-anuais.

As médias mensais correspondentes à TSM do oceano Atlântico Sul desde janeiro de 1982 a dezembro de 2006 foram obtidas do Serviço Climatológico Nacional dos Estados Unidos (NOAA - National Weather Service). Foram consistidas, compiladas e

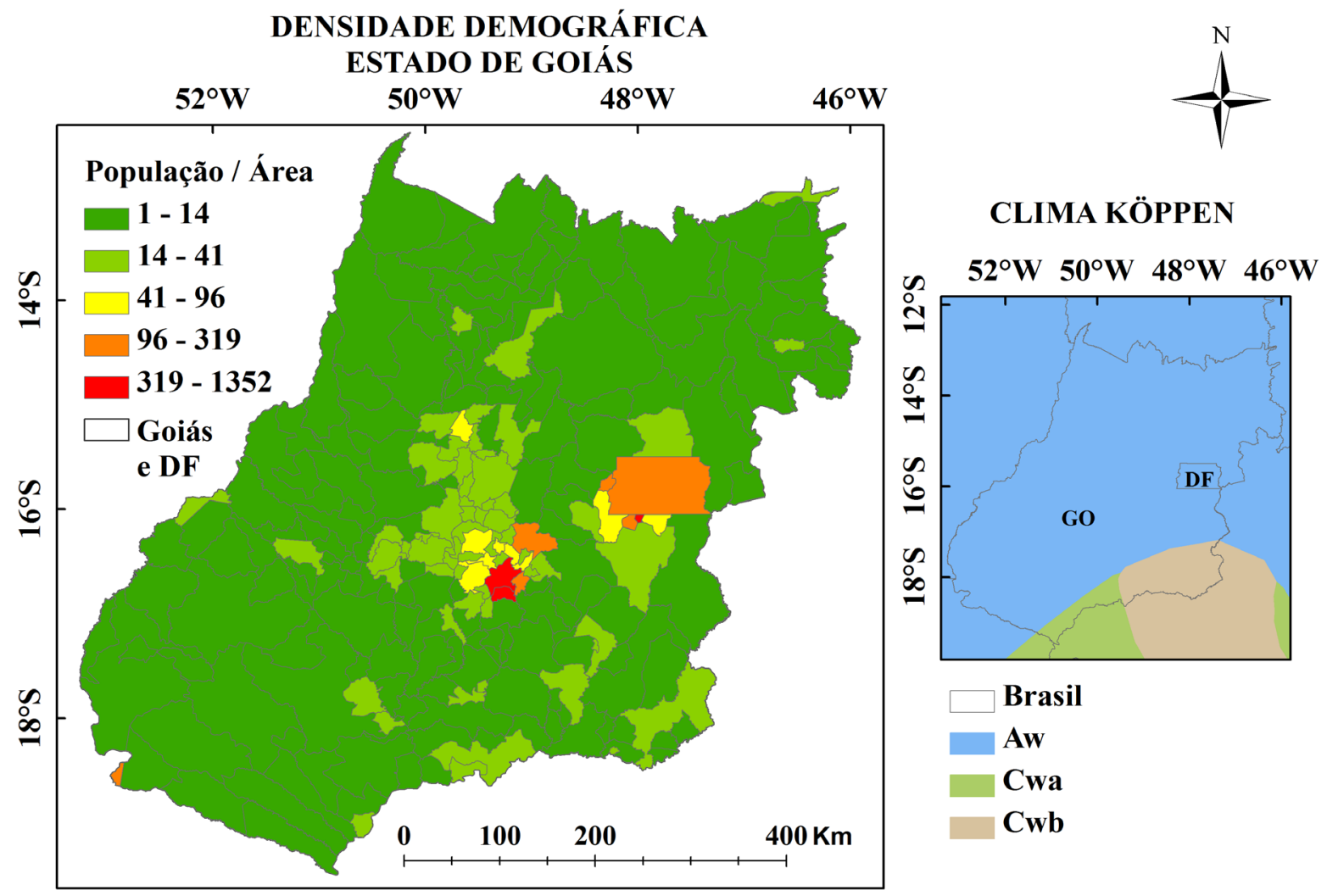

Figura 3.Densidade demográfica e clima do estado deGoiás. 
tratadas juntamente com os dados de precipitação pluvial, durante o período de ago./2011 a jun./2012, permitindo a análise da influência da variação da temperatura no oceano Atlântico Sul no número de dias de chuva do estado de Goiás.

O Índice Oceânico Niño (a) (ION) é um índice que identifica as anomalias da superfície do oceano através de uma média móvel de três meses (Quadro 1). Quando o ION for maior que $+0,5^{\circ} \mathrm{C}$ por no mínimo cinco meses consecutivos o período é caracterizado como El Niño e quando o índice for menor que $-0,5^{\circ} \mathrm{C}$ por no mínimo cinco meses consecutivos o período é caracterizado como La Niña (MENDONÇA e DANNI-OLIVEIRA, 2007). No Quadro 1, observa-se a intensidade do fenômeno ENOS que foi classificada em classes fraca, moderada e forte utilizando-se a média do ION.

Quadro 1. Critérios para classificar a intensidade do fenômeno ENOS usado no estudo.

\begin{tabular}{|c|c|c|}
\hline Evento & Indice Oceânico Niño & Intensidade \\
\hline \multirow{4}{*}{ El Niño } & 0,5 a 0,9 & Fraca \\
\hline & 1,0 a 1,4 & Moderada \\
\hline \multirow{3}{*}{ La Niña } & $\geq 1,5$ & Forte \\
& $-0,5$ a $-0,9$ & Fraca \\
\hline & $-1,0$ a $-1,4$ & Moderada \\
\hline$-3-1,5$ & Forte \\
\hline
\end{tabular}

Fonte: Golden Gate Weather Services (2008).

\section{Resultados e discussão}

A Temperatura da Superfície do Mar (TSM) caracteriza-se pela presença de anomalias negativas e positivas. A anomalia negativa de TSM é marcada pelas águas do oceano mais frias do que o normal. Já a anomalia positiva é associada, por sua vez, pelas águas mais quentes.

Nos meses de janeiro de 1982 a 2006, há uma tendência, conforme o resultado apresentado na Figura 4, de diminuição do número de dias de chuva no estado de Goiás durante as variações de TSM no oceano Atlântico Sul (Figura 4).Na anomalia negativa de TSM para essa série histórica, a temperatura oceânica diminuiu $0,6^{\circ} \mathrm{C}$ pode ser um dos fatores que ocasionou 13 dias de chuva, aproximadamente, no mês de janeiro de 1990 no estado de Goiás.

Em períodos de anomalia positiva de TSM, no Atlântico Sul, a temperatura aumentou até $0,7^{\circ} \mathrm{C}$ e provocou a ocorrência de chuva em aproximadamente 15 dias durante o mês de janeiro de 1998, conforme o gráfico de dispersão e o coeficiente de determinação (R2)apresentado na Figura 4.

Conforme a série histórica utilizada nesse estudo, observou-se que o mês de janeiro de 1985 registrou o maior número de dias de chuva (aproximadamente 24) para um valor de $0,2^{\circ} \mathrm{C}$ de anomalia positiva de TSM nas águas do Atlântico Sul. Ao passo que, o menor número de dias de chuva no estado de Goiás ocorreu em janeiro (aproximadamente 11), sob anomalia negativa de TSM $\left(0,5^{\circ} \mathrm{C}\right)$ no ano de 1993 (Figura 4).

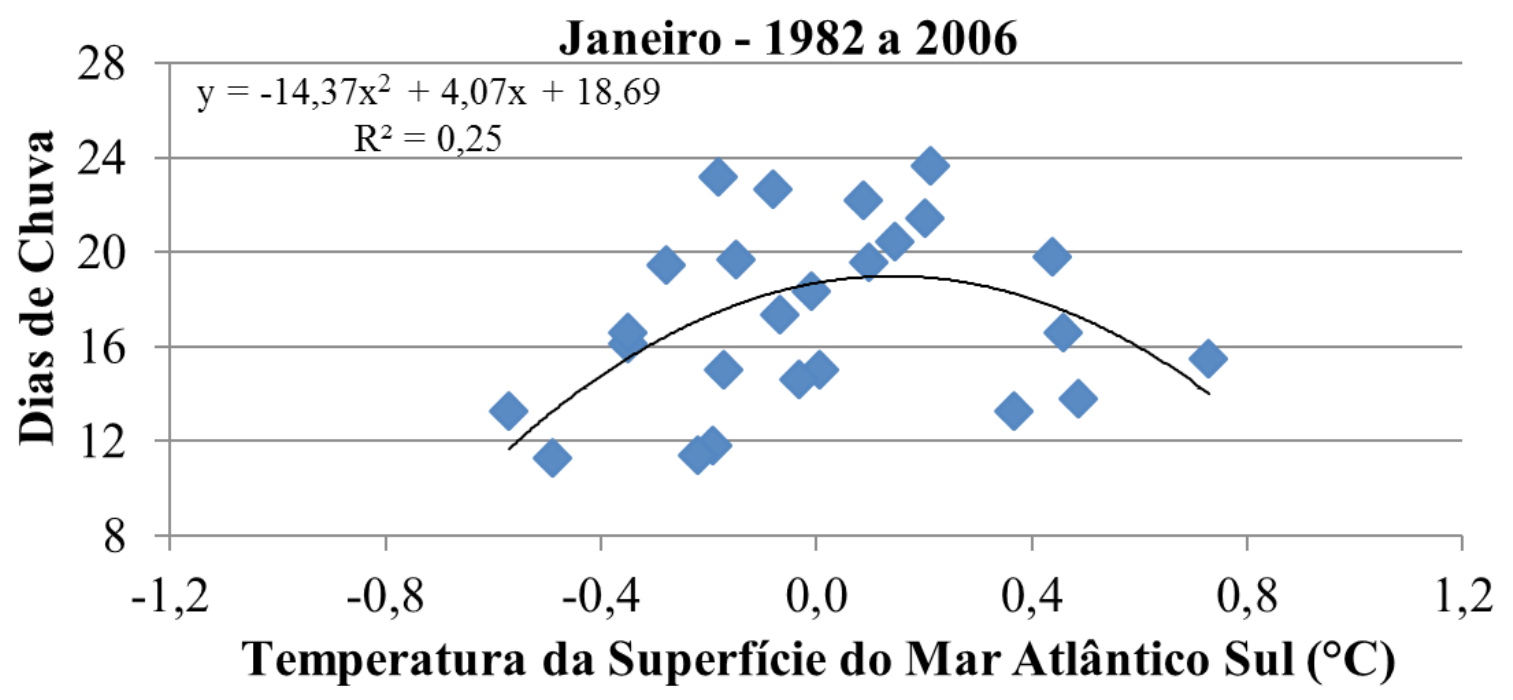

Figura 4. Dispersão em janeiro dos Dias de Chuva em relação à variação daTSM do Atlântico Sul. 


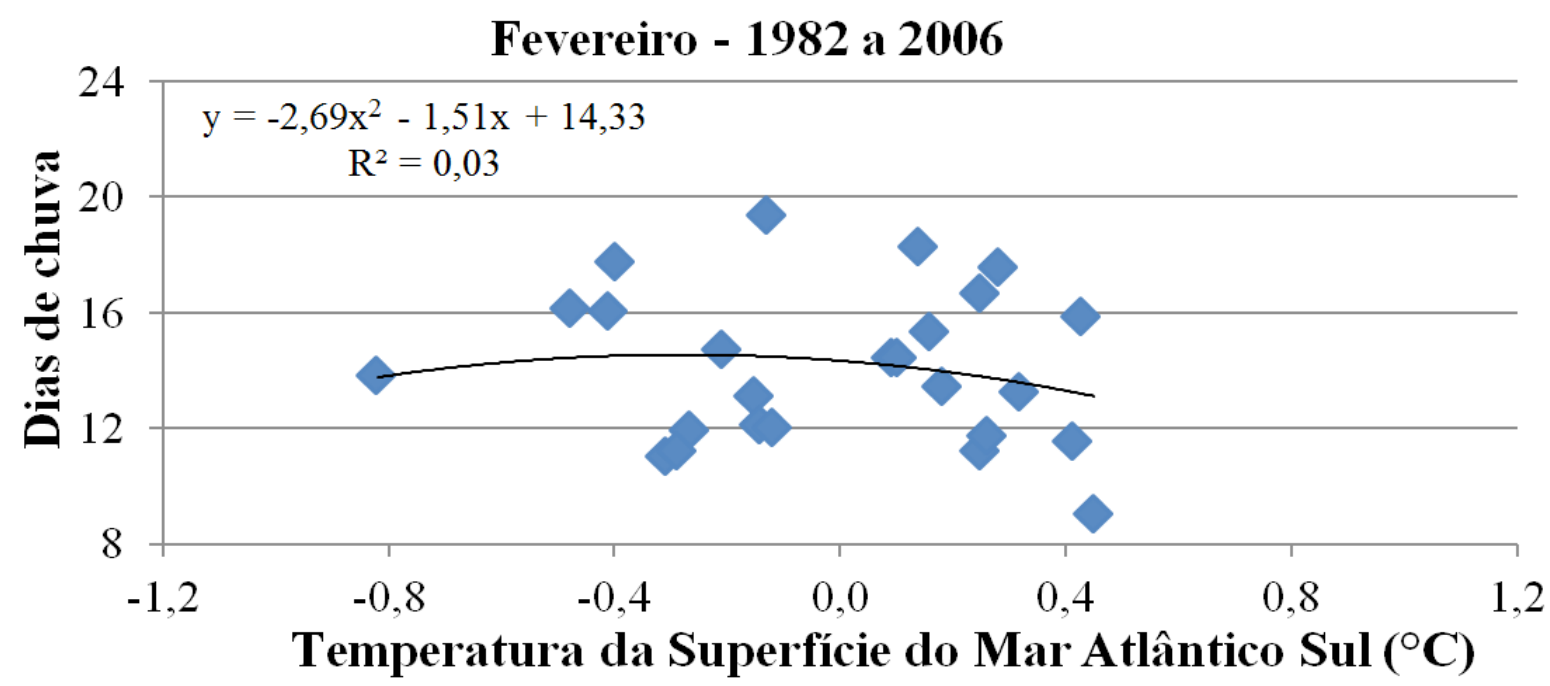

Figura 5. Dispersão em fevereiro dos Dias de Chuva em relação à variação da TSM do Atlântico Sul.

Sob circunstâncias de anomalia negativa de TSM para os meses de fevereiro de 1982 a 2006, a temperatura do oceano Atlântico Sul diminuiu até $0,8^{\circ} \mathrm{C}$ (1997) e provocou, conforme o gráfico de dispersão apresentado e seu coeficiente estatístico de determinação, cerca de 14 dias de chuva ao longo de fevereiro em Goiás (Figura 5).

A maior anomalia positiva registrada para o oceano Atlântico Sul em fevereiro de 1982 a 2006 foi de aproximadamente $0,4^{\circ} \mathrm{C}$ em 2005 , ocasionando 9 dias de chuva, e o máximo número de dias chuvosos verificado para o mesmo período (19 dias em 2004) estava sob anomalia negativa de TSM do oceano (Figura 5).
Nos meses de março da série histórica de 1982 a 2006, a anomalia negativa de TSM das águas do Atlântico Sul, provocou, quanto mais forte fosse sua intensidade, aumento dos dias de chuva em Goiás (Figura 6). No período referente à anomalia de TSM negativa, a temperatura do oceano Atlântico Sul diminuiu até $0,9^{\circ} \mathrm{C}$ provocando um total de 16 dias de chuva, em média, ao longo de março de 1997.

O maior aumento da temperatura das águas do oceano Atlântico Sul, registrado nos meses de março da série de 1982 a 2006, foi de $0,5^{\circ} \mathrm{C}$ (anomalia de TSM positiva) no ano de 1995 provocando 13 dias de chuva ao longo do mês. Observa-se na Figura 6 que tanto o maior número de dias de chuva (aproximadamente

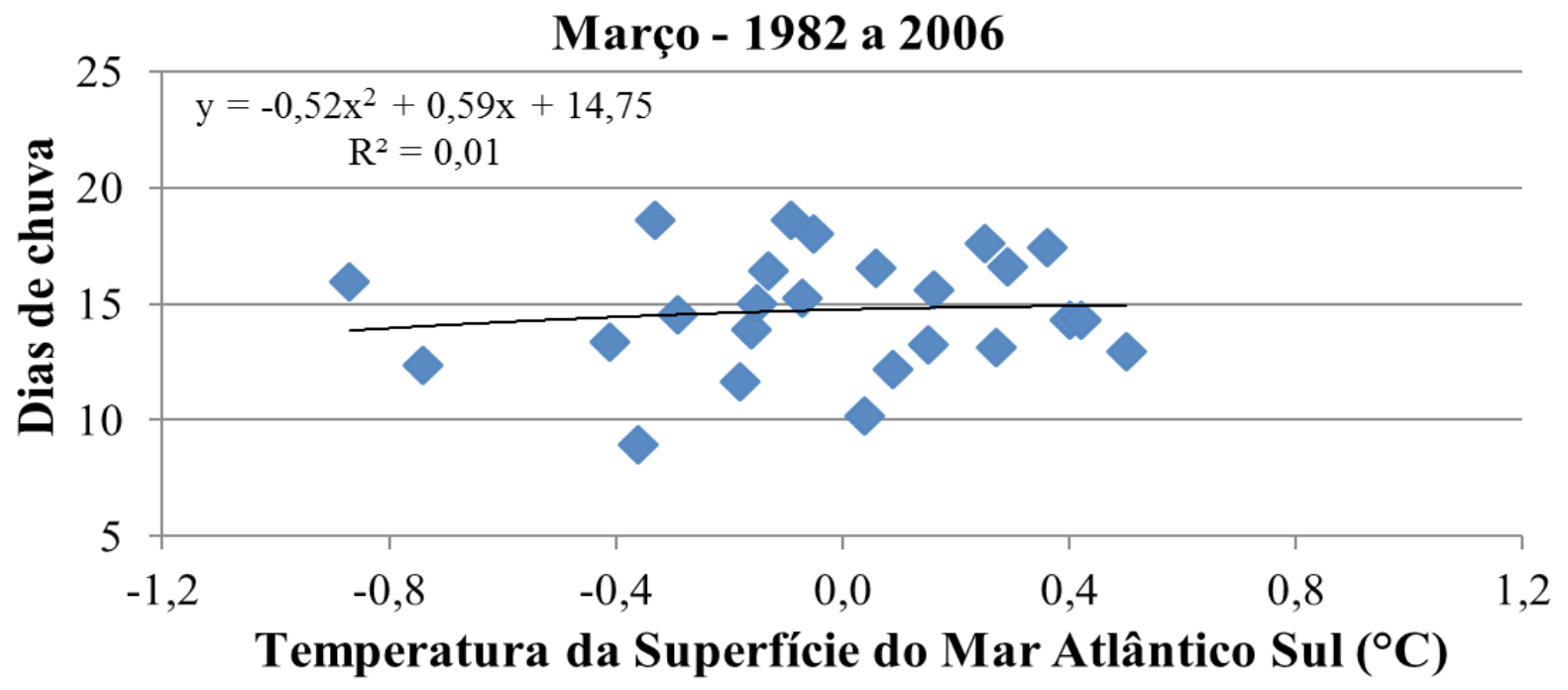

Figura 6. Dispersão em março dos Dias de Chuva em relação à variação da TSM do Atlântico Sul. 


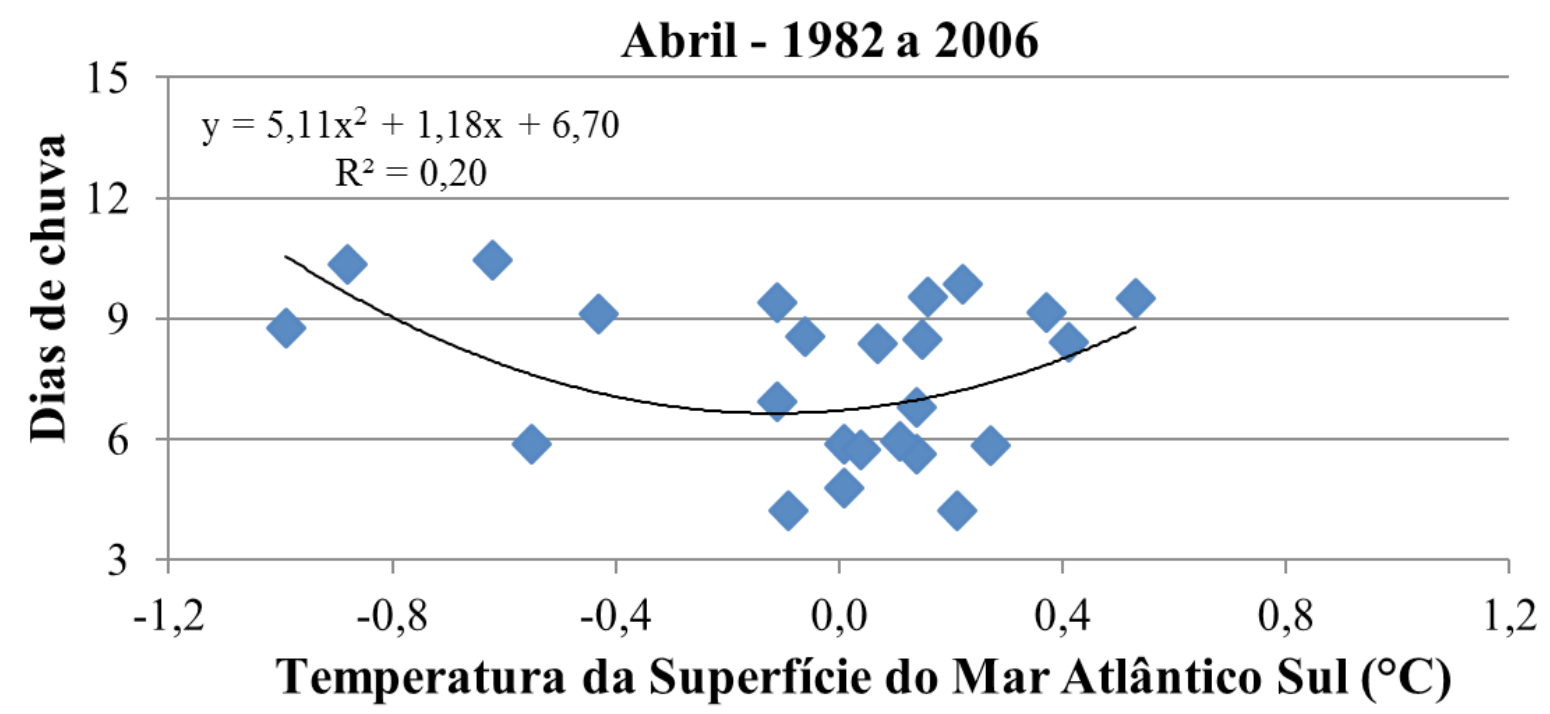

Figura 7. Dispersão em abril dos Dias de Chuva em relação à variação da TSM do Atlântico Sul.

19 dias) quanto o menor (aproximadamente 9 dias) no estado de Goiás, para março de 1982 a 2006, ocorreram em períodos de anomalia negativa de TSM, nos anos de 1991, 1982 e 1993 (Figura 6).

A maior diminuição da temperatura oceânica registrada durante nos meses de abril de 1982 a 2006 foi de $1,0^{\circ} \mathrm{C}$ (anomalia negativa de TSM) no ano de 1997, acarretando um total de 9 dias de chuva, aproximadamente (Figura 7).

Enquanto que a maior anomalia positiva verificada para esta série histórica foi de $0,5^{\circ} \mathrm{C}$ em 1995 e provocou 9 dias de chuva, aproximadamente, no decorrer do mês de abril.

Durante os anos de 1982 a 2006, o maior registro de dias de chuva foi verificado em abril de 2004 (aproximadamente 10 dias) para uma redução de
0,6 ${ }^{\circ} \mathrm{C}$ da temperatura das águas do Atlântico Sul. Os menores registros de dias chuvosos (aproximadamente 4 dias) estavam sob anomalia positiva e negativa de $\operatorname{TSM}\left(0,2^{\circ} \mathrm{C}\right.$ em 1999 e $-0,1^{\circ} \mathrm{C}$ em 2005 , respectivamente (Figura 7).

Nos meses de maio de 1982 a 2006 (Figura 8), houve ligeira tendência, conforme o gráfico de dispersão apresentando, de aumento dos dias de chuva no estado de Goiás durante variações na temperatura da superfície do mar (TSM) do oceano Atlântico Sul. Durante eventos de anomalia negativa de TSM no mês de maio do período histórico considerado, a temperatura oceânica diminuiu até $1,0^{\circ} \mathrm{C}$ ocasionando 2 e 5 dias de chuva, aproximadamente, em 1992 e 1997, respectivamente.

Na anomalia de TSM positiva, a temperatura

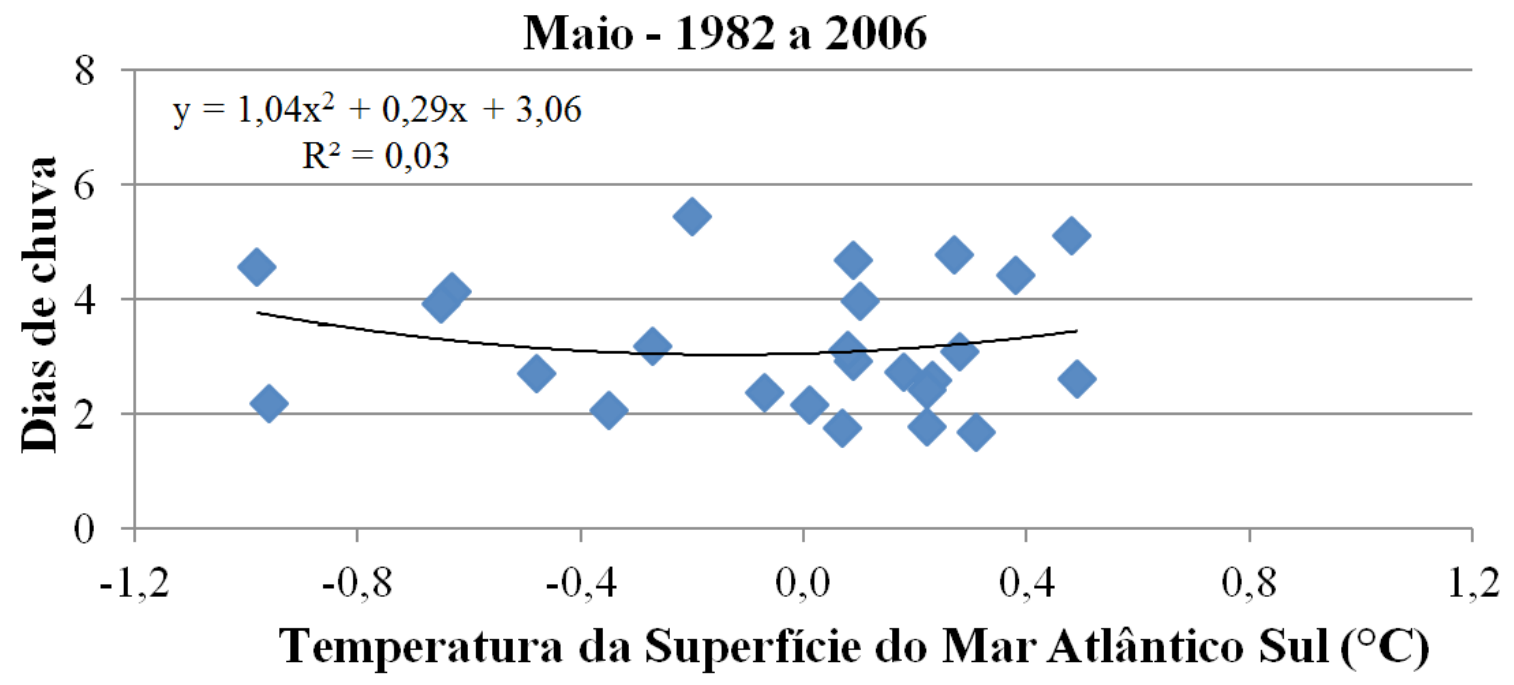

Figura 8. Dispersão em maio dos Dias de Chuva em relação à variação da TSM do Atlântico Sul. 


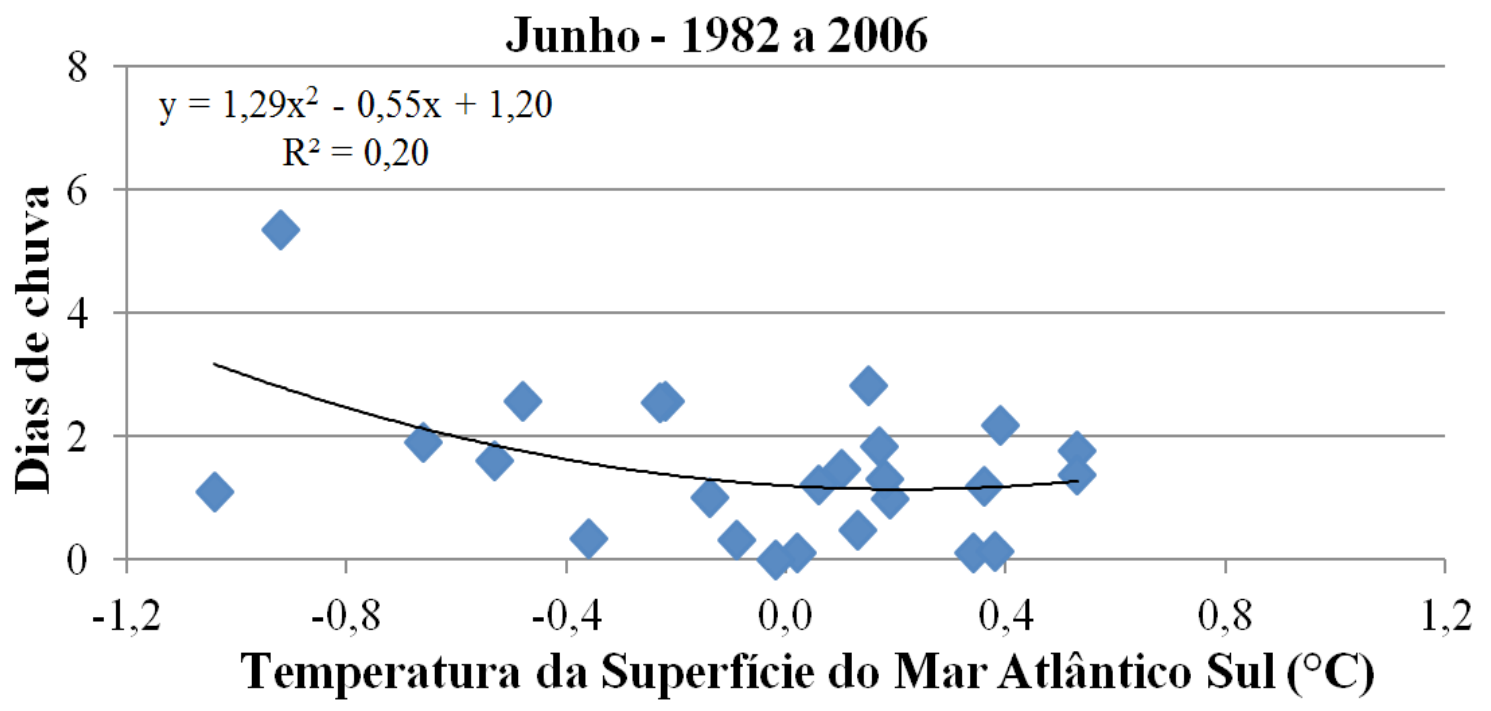

Figura 9. Dispersão em junho dos Dias de Chuva em relação à variação da TSM do Atlântico Sul.

oceânica aumentou até $0,5^{\circ} \mathrm{C}$, ocasionando 3 e 5 dias de chuva, aproximadamente, ao longo do mês de maio, em 1988 e 1996, respectivamente. Observa-se que o maior registro de dias de chuva no mês de maio do período histórico estudado (Figura 8) foi de 5 dias, aproximadamente, no ano de 1990, sob anomalia negativa de $\operatorname{TSM}\left(0,2^{\circ} \mathrm{C}\right)$ nas águas do oceano Atlântico Sul. O ano de 1991 registrou o menor número de dias de chuva no estado de Goiás da série de maio de 1982 a 2006, sob anomalia positiva de TSM equivalente a $0,3^{\circ} \mathrm{C}$ (menos de 2 dias de chuva) (Figura 8).

Durante os meses de junho de 1982 a 2006, de acordo com a Figura 9, houve tendência, conforme o gráfico de dispersão apresentando, de aumento de dias chuvosos em Goiás, nos períodos de anomalia negativa de TSM do Atlântico Sul A partir disso, a temperatura do oceano diminuiu até $1,0^{\circ} \mathrm{C}$ (1992) e provocou1(um) dia de chuva, em média, durante o mês.

A maior anomalia positiva de TSM para a série considerada foi de $0,5^{\circ} \mathrm{C}$ e provocou, conforme o gráfico de dispersão apresentando, aproximadamente, 1 e 2 dias de chuva durante o mês de junho, em 1996 e 1988, respectivamente. Nota-se que o maior registro de dias de chuva para junho de 1982 a 2006, estava sob influência de anomalia negativa de $\operatorname{TSM}\left(0,9^{\circ} \mathrm{C}\right)$ e foi de 5 dias, aproximadamente, no ano de 1997. Ao longo de junho de 2002, não houve nenhum dia de chuva registrado, embora a condição de TSM do Atlântico Sul tenham se mantido estável pela série histórica estudada (Figura 9).

Nota-se uma tendência, pelo gráfico de dispersão apresentado, de diminuição do número de

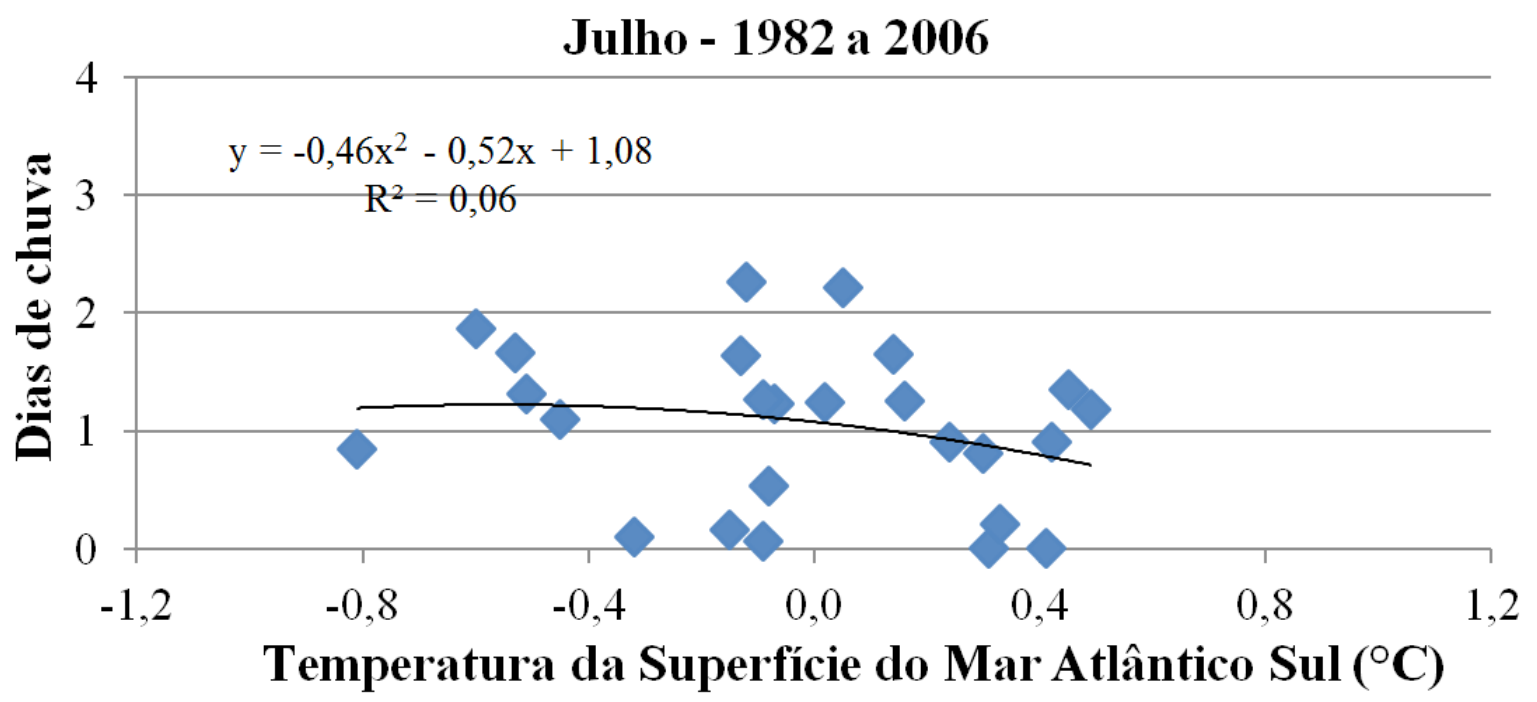

Figura 10. Dispersão em julho dos Dias de Chuva em relação à variação da TSM do Atlântico Sul. 


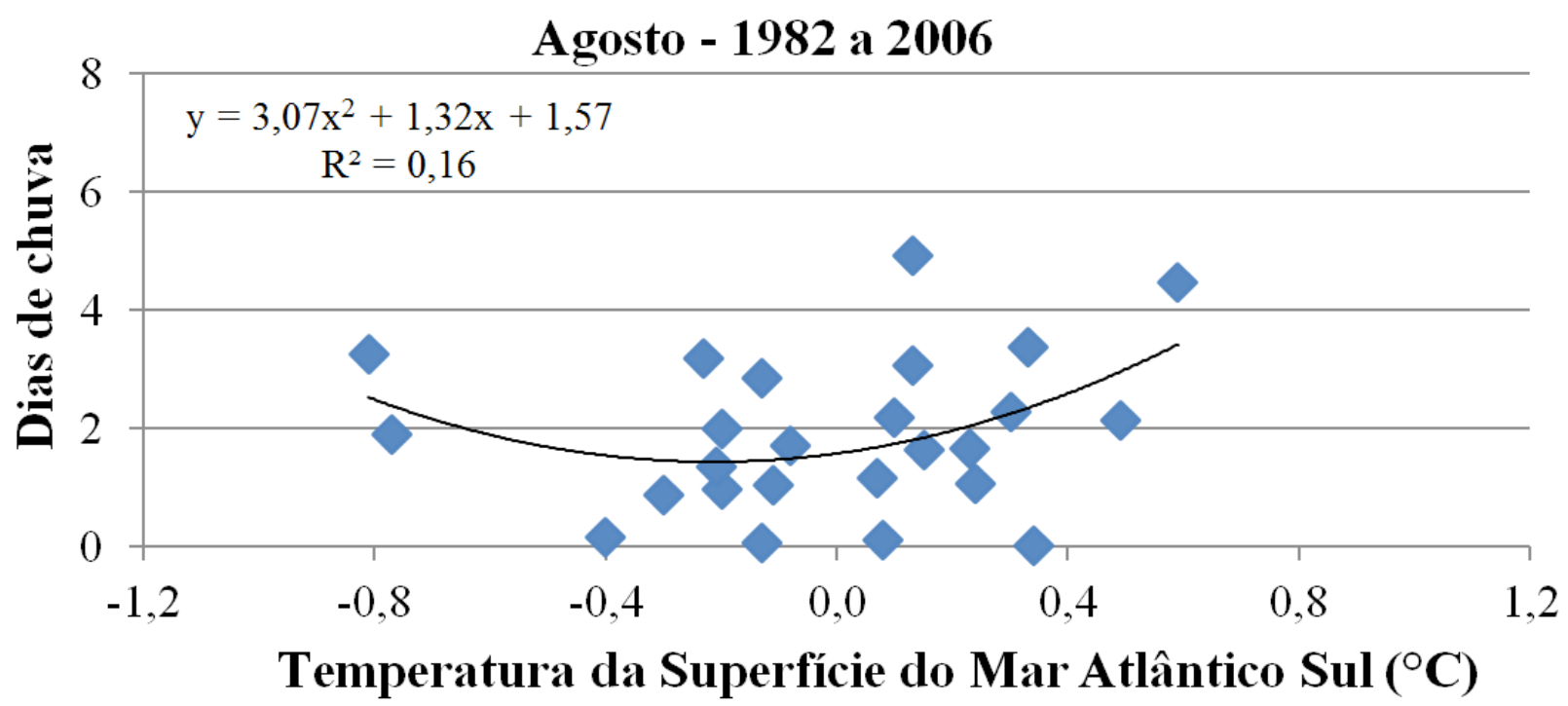

Figura 11. Dispersão em agosto dos Dias de Chuva em relação à variação da TSM do Atlântico Sul.

dias de chuva no estado de Goiás durante as anomalias positivas de TSM do Atlântico Sul, nos meses de julho de 1982 a 2006 (Figura 10). No período de anomalia negativa de TSM para a série em questão, a temperatura oceânica diminuiu até $0,8{ }^{\circ} \mathrm{C}$ e provocou cerca de 1 dia de chuva, em 1992, enquanto a maior anomalia positiva de TSM do Atlântico Sul foi de $0,5^{\circ} \mathrm{C}$ e ocasionou 1 dia de chuva, em média, nos anos de 1996 e 1998 (Figura 10).

Durante esta série de julho, o maior registro de dias de chuva (aproximadamente 2 dias) em Goiás ocorreu durante o ano de 1990 sob anomalia negativa de TSM do Atlântico Sul $\left(0,1^{\circ} \mathrm{C}\right)$. Em 1988 e 2003, não houve nenhum dia de chuva, apesar de anomalia positiva de $\operatorname{TSM}\left(0,4^{\circ} \mathrm{C}\right.$ e $0,3^{\circ} \mathrm{C}$, respectivamente) no estado (Figura 10).
Durante os meses de agosto do período de 1982 a 2006, nota-se uma tendência, pelo gráfico de dispersão apresentado, de aumento do número de dias de chuva em Goiás tanto em fases de anomalia positiva de TSM, quanto em estágios de anomalia negativa (Figura 11). A maior diminuição da temperatura do Atlântico Sul registrada no período em questão foi de $0,8^{\circ} \mathrm{C}$ nos anos de 1992 e 1982, provocando aproximadamente 2 e 3 dias de chuvas no estado de Goiás, respectivamente.

No período de anomalia positiva de TSM o maior aumento da temperatura foi de $0,6^{\circ} \mathrm{C}$ no ano de 1984 provocando, em média, 4 dias de chuva no estado de Goiás. Durante toda a série de agosto de 1982 a 2006, o maior registro de dias de chuva em Goiás foi de, aproximadamente, 5 dias durante período de anomalia positiva das águas do Atlântico Sul

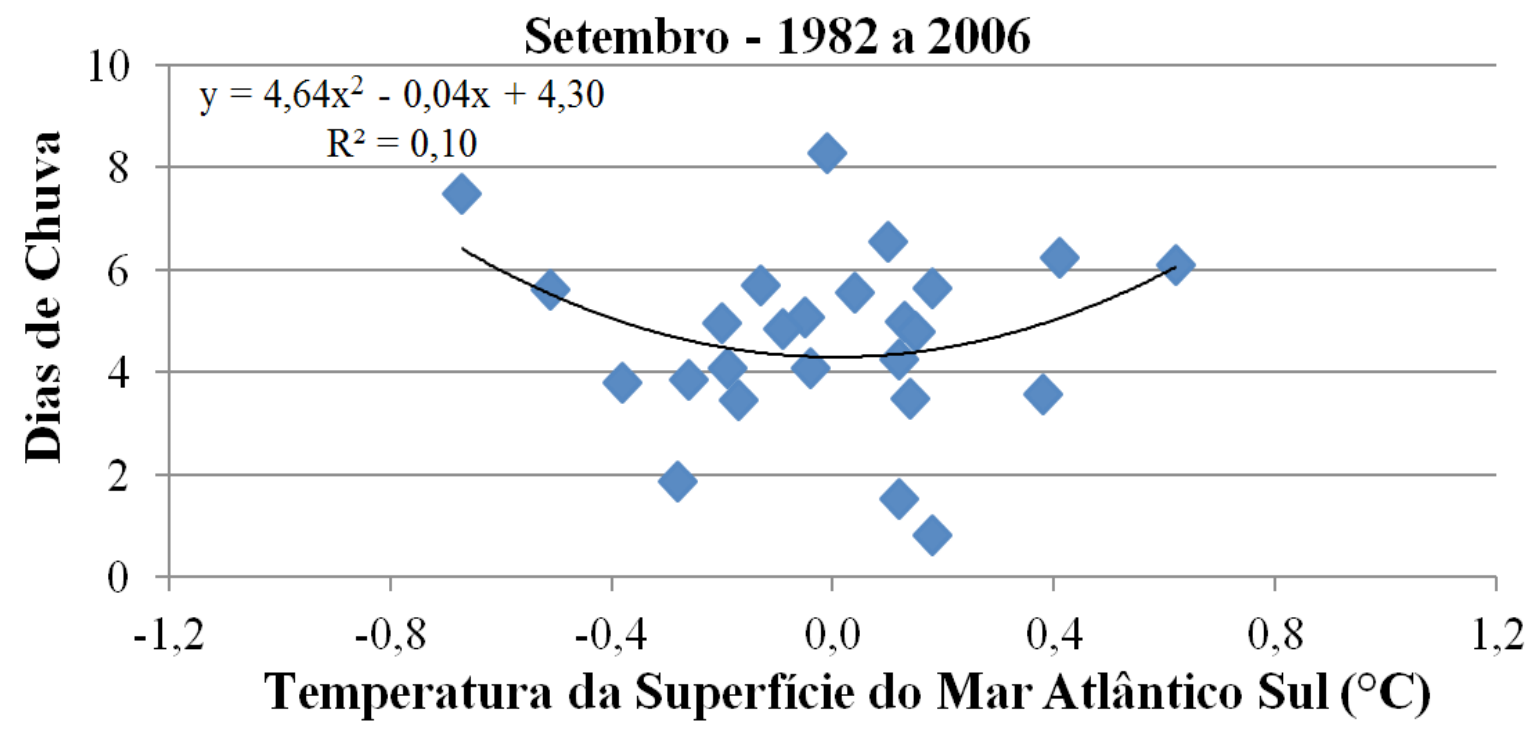

Figura 12. Dispersão em setembro dos Dias de Chuva em relação à variação da TSM do Atlântico Sul. 


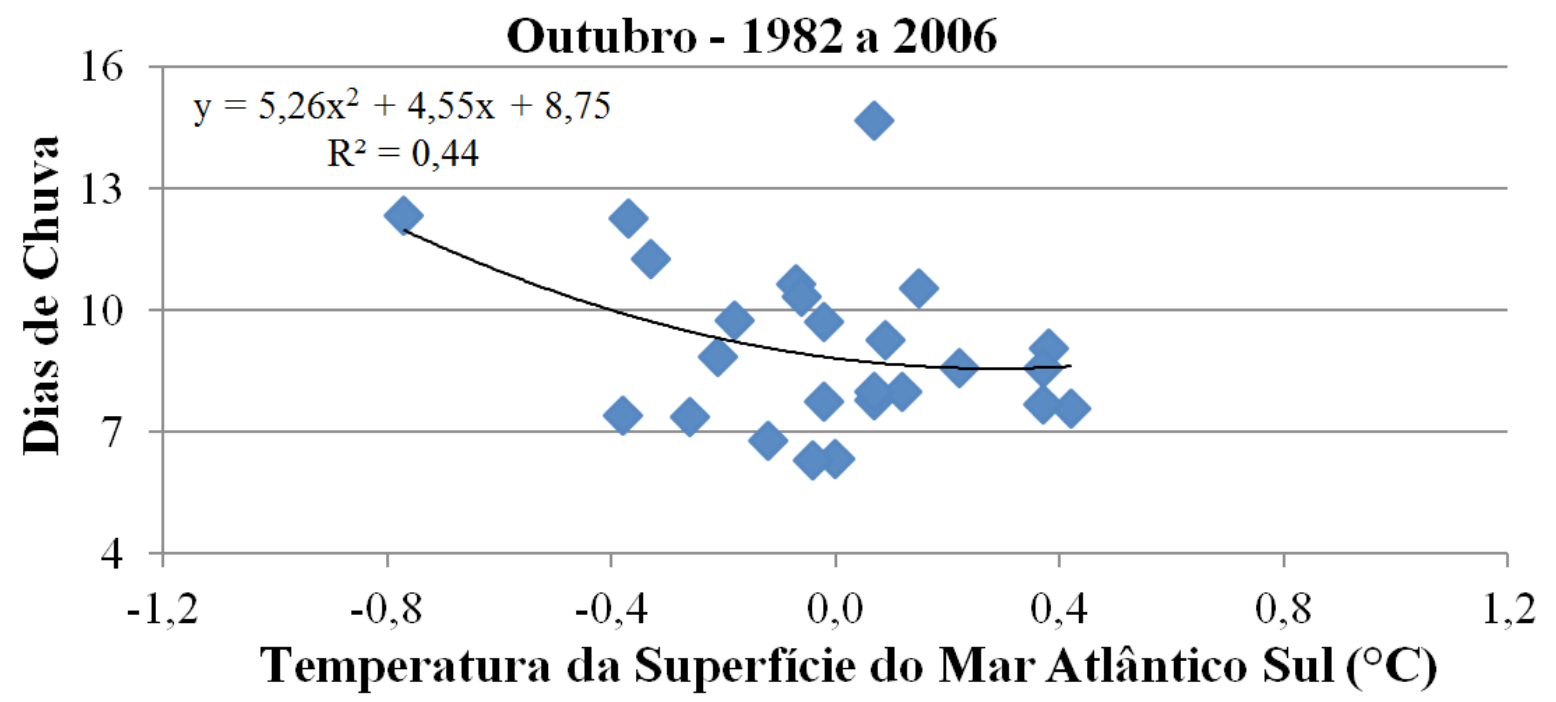

Figura 13. Dispersão em outubro dos Dias de Chuva em relação à variação da TSM do Atlântico Sul.

$\left(0,1^{\circ} \mathrm{C}\right)$, em 1986 . O mês de agosto de 1988 , também sob influência de anomalia positiva de $\operatorname{TSM}\left(0,3^{\circ} \mathrm{C}\right)$,

não registrou ocorrência de chuva (Figura 11).

Conforme demonstra a Figura 12, nos meses de setembro de 1982 a 2006, houve uma tendência, pelo gráfico de dispersão apresentado, de acréscimo dos dias de chuva no estado de Goiás à medida em que a temperatura da superfície do mar no Atlântico Sul variava. Nas fases de anomalia negativa de TSM, a temperatura oceânica diminuiu até $0,7^{\circ} \mathrm{C}$ em setembro de 1992 e ocasionou 7 dias de chuva, aproximadamente, em Goiás, ao longo do mês.

Já em períodos de anomalia positiva de TSM a temperatura oceânica aumentou até $0,6^{\circ} \mathrm{C}$ (1984), ocasionando cerca de 6 dias de chuva durante setembro. $\mathrm{O}$ maior registro de dias de chuva em Goiás, durante esta série histórica de setembro, foi de aproximadamente 8 dias (2000), sob nenhuma influência de TSM $\left(0,0^{\circ} \mathrm{C}\right)$. Já no ano de 2004, registrou-se a menor ocorrência de dias de chuva, aproximadamente 1 dia, durante todo o mês de setembro, sob anomalia positiva de temperatura da superfície do mar equivalente a $0,2^{\circ} \mathrm{C}$ (Figura 12).

A tendência de aumento dos dias de chuva em Goiás nos episódios de anomalia negativa de TSM, nos meses de outubro de 1982 a 2006, pode ser identificada segundo a Figura 13. Durante as fases de anomalia negativa de TSM para esta série, a temperatura do oceano Atlântico Sul diminuiu até $0,8^{\circ} \mathrm{C}$ (1992), anomalia considerada fraca (Quadro 1) e foi correlacionada com chuva em, aproximadamente, 12 dias do mês.

No período em questão, a maior anomalia positiva de TSM do Atlântico Sul registrada foi de $0,4^{\circ} \mathrm{C}$ e provocou, pelo gráfico de dispersão apresentado, de 8 a 9 dias de chuva em Goiás, nos anos de 1993, 2003, 1997 e 1984. O menor registro de dias de chuva para este período de estudo (6 dias) ocorreu nos anos de 2000 e 2005 e não estava sob influência de $\operatorname{TSM}\left(0,0^{\circ} \mathrm{C}\right)$. Já o maior registro de dias de chuva estava sob condição de anomalia positiva de TSM equivalente a $0,1^{\circ} \mathrm{C}$ e provocou, em média, 15 dias de chuva no estado em 2006 (Figura 13).

Nos meses de novembro da série de 1982 a 2006, a variação da TSM, no Atlântico Sul, provocou, pelo gráfico de dispersão apresentado, um ligeiro aumento de dias de chuva em Goiás (Figura 14). A maior anomalia negativa de TSM verificada em novembro da série histórica considerada ocorreu no ano de 1992 e a temperatura do oceano Atlântico Sul diminuiu até $0,8^{\circ} \mathrm{C}$ provocando, aproximadamente, 15 dias de chuva no estado de Goiás.

A maior TSM do Atlântico Sul registrado em novembro desta série de 1982 a 2006 foi de $0,7^{\circ} \mathrm{C}$ no ano de 1997 e provocou, aproximadamente, 14 dias de chuva em Goiás. Observa-se também, na Figura 14, que o maior registro de dias de chuva, aproximadamente, 17 dias em novembro de 1983, estava sob anomalia negativa de $\operatorname{TSM}\left(0,1^{\circ} \mathrm{C}\right)$, enquanto o menor registro de dias de chuva para o mesmo período foi, aproximadamente, 8 dias em novembro de 1986, também sob anomalia negativa de $\operatorname{TSM}\left(0,2^{\circ} \mathrm{C}\right)$ do oceano Atlântico Sul (Figura 14).

Os episódios de anomalia negativa de TSM do Atlântico Sul foram marcados por aumento dos dias de chuva ao longo da série de dezembro de 1982 a 2006. A 


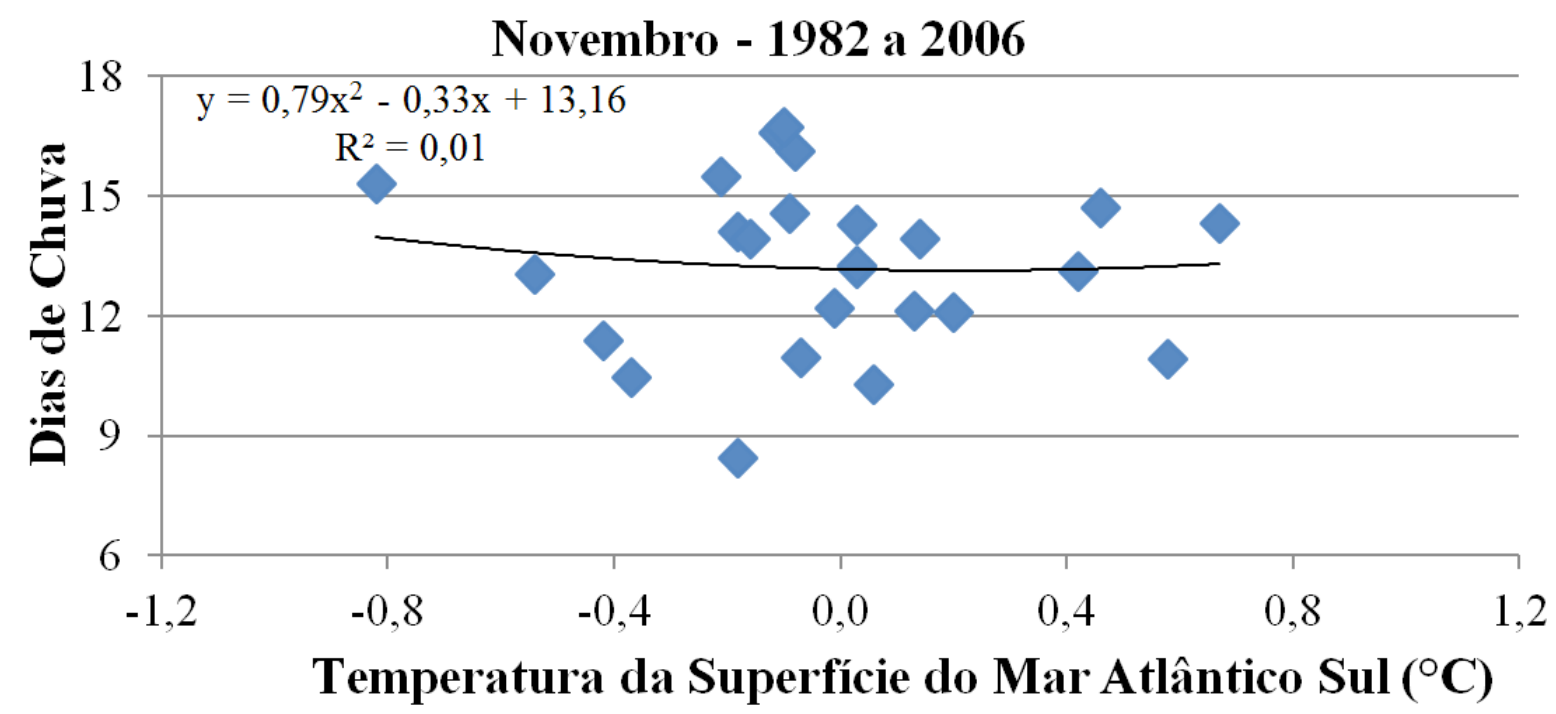

Figura 14. Dispersão em novembro dos Dias de Chuva em relação à variação da TSM do Atlântico Sul.

maior anomalia negativa de TSM registrou diminuição de até $0,7^{\circ} \mathrm{C}$ (1992) na temperatura do Atlântico Sul ocasionando, pelo gráfico de dispersão apresentado, aproximadamente, 18 dias de chuva ao longo do mês de dezembro em Goiás. Em 1997, a temperatura do oceano aumentou até $0,8^{\circ} \mathrm{C}$ e ocasionou 16 dias de chuva, aproximadamente, no estado (Figura 15).

O maior registro de dias de chuva em dezembro do período histórico estudado foi de 23 (1989), para um valor, de anomalia negativa de TSM de $0,5^{\circ} \mathrm{C}$ das águas do Atlântico Sul. Ao passo que o menor registro de dias de chuva em Goiás para o mês de dezembro da série de 1982 a 2006 foi de, aproximadamente, 12 dias (1990), sob valor positiva de TSM do Atlântico Sul de $0,1^{\circ} \mathrm{C}$ (Figura 15).
Observa-se um acentuado aumento no número de dias de chuva em Goiás nas fases de anomalia negativa deTSM e um decréscimo no período de anomalia positiva de TSM do Atlântico Sul, na série histórica de 1982 a 2006 (Figura 16). Na fase mais intensa de anomalia negativa de TSM, em 1992, a temperatura do Atlântico Sul diminuiu, aproximadamente, $0,7^{\circ} \mathrm{C}$ e ocasionou 118 dias de chuva ao longo do ano, no estado de Goiás (Figura 16).

As maiores anomalias positivas registradas para o período de estudo foram nos anos de 1988, 1984, 2003 e 1998, onde a TSM do Atlântico Sul atingiu até $0,3^{\circ} \mathrm{C}$ e provocou cerca de99, 101, 102 e 105 dias de chuva, respectivamente, no estado (Figura 16).

Sob influência de anomalia negativa, a TSM

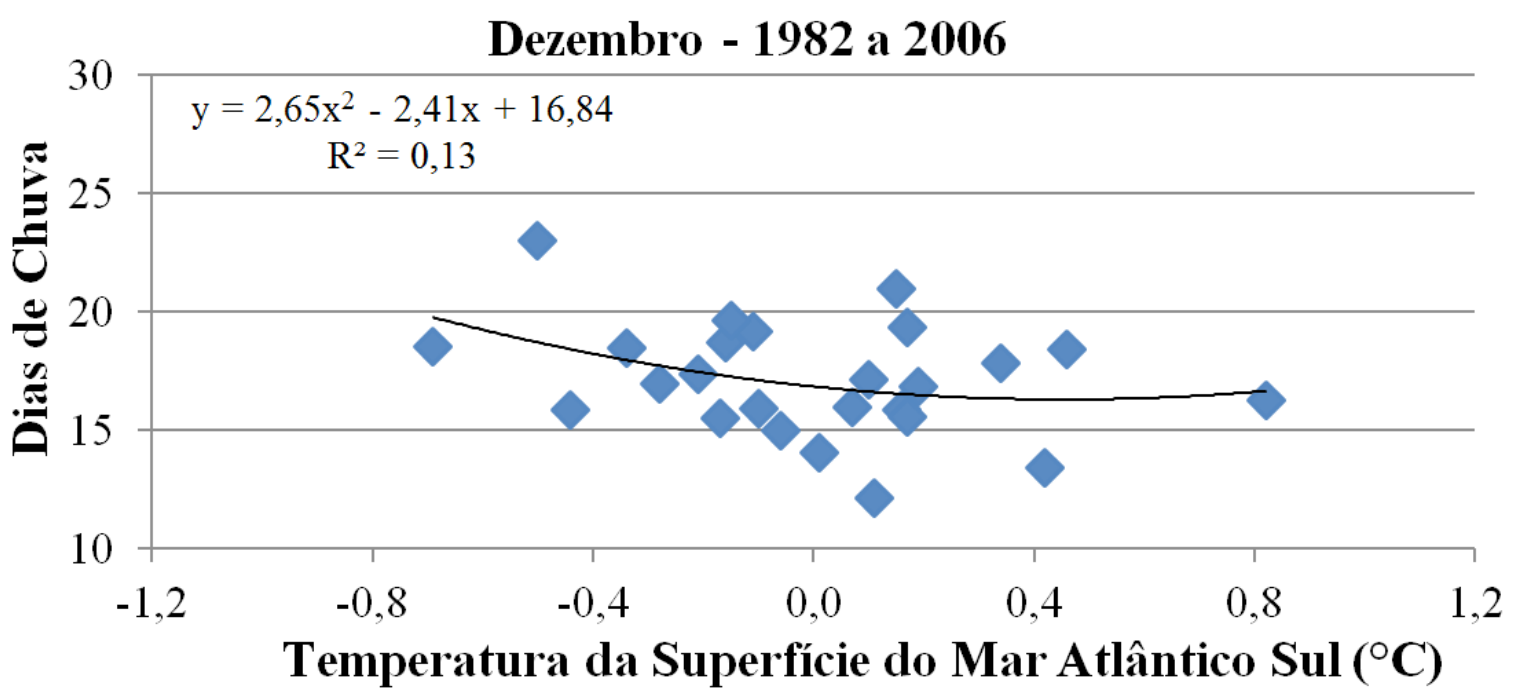

Figura 15. Dispersão em dezembro dos Dias de Chuva em relação à variação da TSM do Atlântico Sul. 


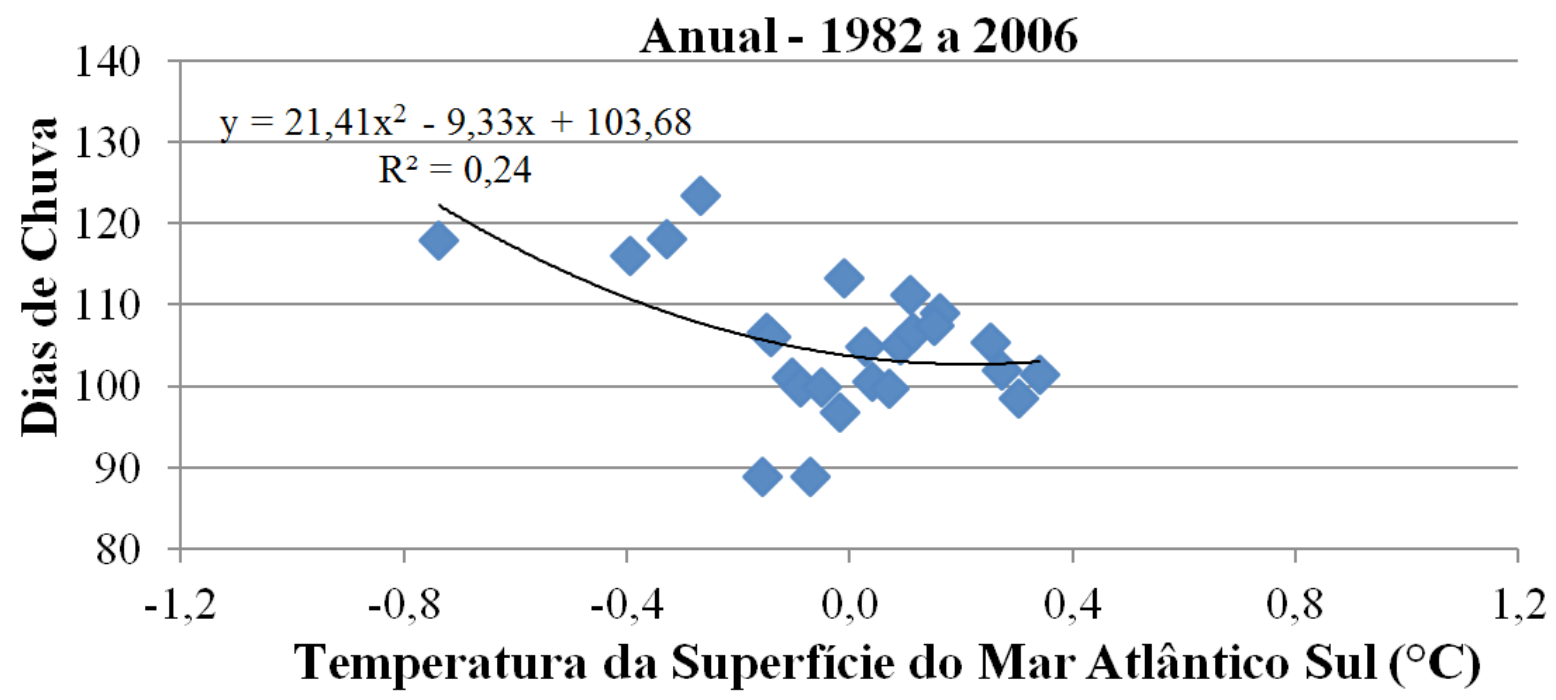

Figura 16. Dispersão da Média Anual de Dias de Chuva em relação à variação da TSMdo Atlântico Sul no período.

do Atlântico Sul diminui até $0,2^{\circ} \mathrm{C}$ no ano de 2002 e registrou o menor número de dias de chuva (aproximadamente 89) em Goiás. Enquanto que o ano de 1983 registrou o maior número de dias de chuva no estado (123 dias, aproximadamente) em circunstâncias de anomalia negativa de TSM equivalente a $0,3^{\circ} \mathrm{C}$ (Figura 16).

A Figura 17 correlaciona, em vermelho, a redução ou aumento da temperatura do oceano Atlântico Sul com o volume de precipitação (colunas azuis) no estado de Goiás, durante a série de 1982 a 2006.

Durante episódios de anomalia negativa de TSM do Atlântico Sul, durante os anos de 1982 a 2006, a menor temperatura registrada foi de $-1,0^{\circ} \mathrm{C}$ nos meses de maio e junho do ano de 1992, ocasionando, em Goiás, durante as respectivas manifestações, 2 dias e 1 dia de chuva, aproximadamente (Figura 17).

O episódio mais intenso de anomalia positiva de TSM, durante o mesmo período, ocorreu em dezembro de 1997 e o maior aumento de TSM do Atlântico Sul foi de $0,8^{\circ} \mathrm{C}$ ocasionando, aproximadamente, 16 dias de chuva no total (Figura 17).

Verifica-se que o maior registro de dias de chuva em Goiás (aproximadamente 24 dias), ao longo da série de 1982 a 2006, foi no mês de janeiro de 1985 (Tabela1), sob um valor de $0,2^{\circ} \mathrm{C}$ de anomalia positiva de TSM do Atlântico Sul (Figura 4).

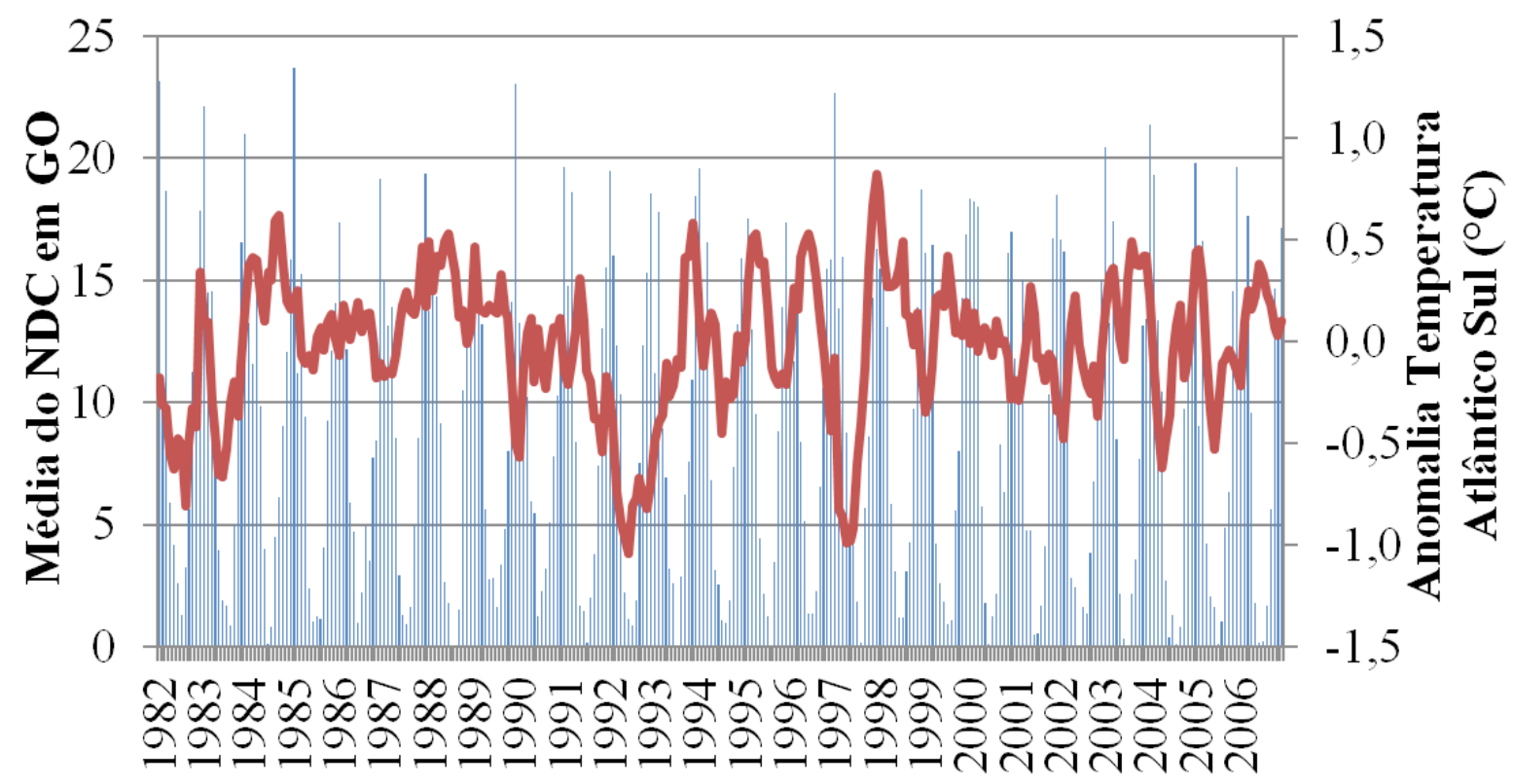

Figura 17. Influência da variação da TSM no Atlântico Sul nos Dias de Chuva do estado de Goiás no período de 1982 a 2006. 
Tabela 1.Estatística dos dias de chuva no estado de Goiás.

\begin{tabular}{cccccc}
\hline \multicolumn{5}{c}{ Máximo Média Mediana Mínimo } & $\begin{array}{c}\text { Desvio } \\
\text { Padrão }\end{array}$ \\
Jan & 23,7 & 17,3 & 16,6 & 11,2 & 3,8 \\
Fev & 19,3 & 14,1 & 13,8 & 9,0 & 2,7 \\
Mar & 18,6 & 14,7 & 14,6 & 8,9 & 2,5 \\
Abr & 10,4 & 7,4 & 8,4 & 2,8 & 2,2 \\
Mai & 5,5 & 3,2 & 2,9 & 1,7 & 1,1 \\
Jun & 5,4 & 1,5 & 1,3 & 0,0 & 1,2 \\
Jul & 2,3 & 1,0 & 1,2 & 0,0 & 0,7 \\
Ago & 4,9 & 1,9 & 1,7 & 0,0 & 1,3 \\
Set & 8,3 & 4,7 & 4,9 & 0,8 & 1,7 \\
Out & 14,7 & 9,1 & 8,6 & 6,3 & 2,0 \\
Nov & 16,7 & 13,3 & 13,3 & 8,5 & 2,1 \\
Dez & 23,0 & 17,1 & 17,0 & 12,2 & 2,4 \\
\hline \hline
\end{tabular}

A medida do grau de dispersão dos valores em relação ao seu valor médio mostra que, em média, nos meses mais chuvosos, o desvio padrão foi maior que nos meses secos. O maior desvio padrão $(3,8)$ foi obtido no mês de janeiro, considerado mês chuvoso, e o menor foi obtido em julho $(0,7)$, considerado mês seco (Tabela 1).

A tendência central (média), que é o centro de um grupo de números em uma distribuição estatística, para os dias de chuva, mostrou uma maior proximidade com os valores máximos nos meses chuvosos (outubro a abril) em relação aos meses secos (maio a setembro), os quais tiveram proximidade com os valores mínimos. Tanto nos meses mais úmidos quanto nos meses secos, verifica-se que a mediana ficou muito próxima da média (Tabela 1).

\section{Conclusão}

Este estudo detectou a influência exercida pelas anomalias (positiva e negativa) de TSM no sul do oceano Atlântico na precipitação pluvial do estado do Goiás e confirmou que, durante a série histórica de 1982 a 2006, os episódios de anomalia positiva de TSM manifestaram-se nos anos de 1984, 1988, 1995, 1996, 1997, 1998, 2003 e 2005. As fases de anomalia negativa de TSM foram registradas nos anos de 1982, 1984, 1990, 1992, 1993, 1997 e 2003.

A análise estatística realizada neste estudo indicou que, durante os anos de 1982 a 2006, o mês de janeiro de $1985\left(0,2^{\circ} \mathrm{C}\right.$ acima da média histórica nas águas do Atlântico Sul) registrou o máximo número de dias chuvosos em Goiás (24 dias), enquanto os meses de julho de $1988\left(0,4^{\circ} \mathrm{C}\right)$, agosto de $1988\left(0,3^{\circ} \mathrm{C}\right)$, junho de $2002\left(0,0^{\circ} \mathrm{C}\right)$, e julho de $2003\left(0,3^{\circ} \mathrm{C}\right)$ não registraram ocorrência de chuva no estado. Logo, os valores máximos e mínimos de precipitação observados neste estudo não estavam sob influência forte de TSM (devido aos gráficos de dispersão apresentados nos resultados).

De acordo com este estudo, conclui-se que o episódio mais intenso de anomalia positiva de TSM da série histórica de 1982 a 2006 aumentou a temperatura das águas do oceano Atlântico Sul em $0,8^{\circ} \mathrm{C}$ em dezembro de 1997 provocando 16 dias de chuva no estado de Goiás. Quanto à atuação da anomalia negativa de TSM, este estudo revelou que a temperatura das águas do Atlântico Sul diminuiu até $1,0{ }^{\circ} \mathrm{C}$ registrando, portanto, a intensidade mais forte do fenômeno durante o período de 1982 a 2006, e ocasionou 1 (junho de 1992), 2 (maio de 1992), 5 (maio de 1997) e 9 (abril de 1997) dias de chuva no estado de Goiás.

\section{Agradecimentos}

Os autores agradecem à CPRM/SGB (Companhia de Pesquisa de Recursos Minerais / Serviço Geológico do Brasil)pelo fomento que viabilizou o desenvolvimento deste trabalho.

\section{Referências}

ALVES, J. M. B.; SOUZA, R. O.; CAMPOS, J. N. B. Previsão da anomalia de Temperatura da Superfície do Mar (TSM) no Atlântico Tropical, com a equação da difusão de temperatura.Revista Climanálise, Instituto Nacional de Pesquisas Espaciais - INPE, Ano 03, n.1, 2006, pp.6- 19.

Costa, H.; Marcuzzo, F.; Ferreira, O.; Andrade, L. Espacialização e Sazonalidade da Precipitação Pluviométrica do Estado de Goiás e Distrito Federal.Revista Brasileira de Geografia Física, v. 5, n.1, pág. 87-100. 2012.Disponível em: <http://www. revista.ufpe.br/rbgfe/index.php/revista/article/ view/291/254>. Acesso em: 09 jul. 2013.

CARDOSO, M. R. D.; MARCUZZO, F. F. N.; MELO, D. C. R. Mapeamento temporal e espacial da precipitação pluviométrica da região metropolitana de Goiânia. In: SIMPÓSIO BRASILEIRO DE SENSORIAMENTO REMOTO, 
15, 2011, Curitiba-PR. ANAIS... Curitiba: INPE e SELPER do Brasil, 2011. Disponível em: <http:// www.dsr.inpe.br/sbsr2011/files/p0424.pdf>. Acesso em: 29 abr. 2013.

EMBRAPA. Empresa Brasileira de Pesquisa Agropecuária.Brasil em Relevo. Disponível em: <http://www.relevobr.cnpm.embrapa.br/ download/index.htm>. Acesso em: 18 dez. 2011.

\section{GOLDEN GATE WEATHER SERVICES. ENSO}

Years based on Oceanic Niño Index (ONI). Disponível em: <http://ggweather.com/enso/oni. htm>. Acesso em: 15 nov. 2008.

IBGE. (2010). Estatística Populacional - Censo 2010. Disponível em <http://www.ibge.gov.br/ cidadesat/link.php?uf=to $>$. Acesso em: 10 mai. 2013.

MARCUZZO, F. F. N.; OLIVEIRA, N. de L.; CARDOSO, M. R. D. Tendência do número de dias de chuva no estado do Mato Grosso. Ciência e Natura. 2012. v. 34, n. 2. p. 59-82. Disponível em: $<$ http://cascavel.ufsm.br/revista_ccne/ojs/index. $\mathrm{php} /$ cienciaenatura/article/view/798/550>. Acesso em: 12 mai. 2013.

Marcuzzo, F. F. N.; oliveira, n. L.; CARDOSO, M. R. D. Tendência do Número de Dias de Chuva no Estado do Mato Grosso do Sul e Sua Relação com o Fenômeno ENOS. Revista Brasileira de Geografia Física, v. 5, n. 5, pág. 1133-44. 2012. Disponível em: <http://www.revista.ufpe.br/rbgfe/ index.php/revista/article/view/360/343>. Acesso em: 09 jul. 2013.

MENDONÇA, FRANCISCO; DANNI-OLIVEIRA, INÊS MORESCO. Climatologia: noções básicas e climas do Brasil. São Paulo: Oficina de Textos, 2007, 206p.

NOAA - National Weather Service (2011). Monthly Atmospheric \& SST Indices. Disponível em <http:// www.cpc.ncep.noaa.gov/data/indices/>.Acesso em: 19 mai. 2013.

PEREIRA, V. C.; SOBRINHO, J. E.; OLIVEIRA, A. D.; VIEIRA, R. Y. M.; MELO, T. K.; MELO, S. B.; SILVA, F. G. Influência dos eventos El Niño e La Niña na precipitação pluviométrica de Mossoró-RN. In: CONGRESSO BRASILEIRO DE METEOROLOGIA, 16, 2010, Belém-PA. Anais eletrônicos. Belém: SBMET, 2010. Disponível em: <http://www.cbmet2010.com/anais/ artigos/60_46462.pdf>. Acesso em: 02 jan. 2012.

PINTO, E. J. de A.; AZAMBUJA, A. M. S. de; FARIAS, J. A. M.; SALGUEIRO, J. P.de B.; PICKBRENNER, K. (Coords.). (2011). Atlas pluviométrico do Brasil: isoietas mensais, isoietas trimestrais, isoietas anuais, meses mais secos, meses mais chuvosos, trimestres mais secos, trimestres mais chuvosos. Brasília: CPRM, 1 DVD. Escala 1.5:000.000. Equipe Executora: Andressa Macêdo Silva de Azambuja; Margarida Regueira da Costa; Carlos Eduardo de Oliveira Dantas; José Alexandre Moreira Farias; Érica Cristina Machado;Francisco Marcuzzo; Vanesca Sartorelli Medeiros; Denise Chistina de Rezende Melo; Jean Ricardo da Silva do Nascimento; Paulo de Tarso R.Rodrigues ; André Luis M. Real dos Santos ; Adriana Burin Weschenfelder ; Sistema de Informação Geográfica-SIG versão 2.0 - atualizada em novembro/2011; Programa Geologia do Brasil; Levantamento da Geodiversidade. Disponível em: <http://www. cprm.gov.br/publique/media/Isoietas_Totais_ Anuais_1977_2006.pdf >. Acesso em: 15 jun. 2013.

ROMERO, V.; MARCUZZO, F. F. N. Influência do El Niño e La Niña no número de dias de precipitação pluviométrica do estado de Goiás. ACTA Geográfica, Boa Vista, v.7, n.14, jan./abr. de 2013. pp.93-106. Disponível em: <http://revista. ufrr.br/index.php/actageo/article/view/788/1030>. Acesso em: 10 mai. 2013.

SANTOS, C. A. C.; MANZI, A. O. Eventos extremos de precipitação no estado do Ceará e suas relações com a temperatura dos Oceanos Tropicais. Revista Brasileira de Meteorologia, São Paulo, v.26, n.1, pp. 157 - 165, 2011. Disponível em: <http://www.scielo.br/scielo.php?pid=S010277862011000100014\&script=sci_arttext $>$. Acesso em: 10 mai. 2013.

SIEG. Sistema Estadual de Estatística e Informações Geográficas de Goiás. Disponível em:<http://www.sieg.go.gov.br>. Acesso em: 16 dez. 2011.

SOARES, S. C.; MOURA, C. R. W.; COLTRI, P. P.; JÚNIOR, C. M. Efeitos do El Niño e da La Niña na Agricultura Brasileira. Instituto Nacional de Pesquisas Espaciais - INPE. Disponível em: $<$ http://www7.cptec.inpe.br/noticias/noticia/8530>. Acesso em: 28 maio 2012. 